\title{
Low Serum Uric Acid Level Is a Risk Factor for Death in Incident Hemodialysis Patients
}

\author{
S.M. Kurt Lee ${ }^{a}$ Andrew L. Lee ${ }^{a}$ Thomas J. Winters $^{a}$ Emily Tam $^{a}$ \\ Mohammed Jaleel $^{\mathrm{a}}$ Peter Stenvinkel $^{\mathrm{b}}$ Richard J. Johnson ${ }^{\mathrm{c}}$ \\ ${ }^{a}$ Biotronics Kidney Center, Beaumont, Tex., USA; ${ }^{b}$ Department of Renal Medicine K56, Institution of Clinical \\ Investigation and Technology, Karolinska University Hospital at Huddinge, Karolinska Institute, Stockholm, Sweden; \\ 'University of Florida, Gainesville, Fla., USA
}

\section{Key Words}

Hypoalbuminemia $\cdot$ Hemodialysis, comorbidity $\cdot$ Serum uric acid, mortality

\begin{abstract}
Background: A reverse epidemiology of classic cardiovascular risk factors was observed in hemodialysis patients with a high comorbidity burden. We hypothesized that uric acid, a novel cardiovascular risk factor, also has an altered association with survival in these patients. Methods: A retrospective study was conducted on 168 consecutive outpatient hemodialysis patients over a 6-year period. Serum uric acid, albumin levels and relevant laboratory information were recorded monthly. The disease severity was assessed using Comorbidity Index (Col) scores. Patients were stratified into 3 groups according to their serum uric acid concentrations: group I was the lowest quintile, group || was the middle 3 quintiles and group III was the highest quintile. The risks of death were calculated utilizing a Cox regression model. $\boldsymbol{R} \boldsymbol{e}$ sults: Using group II as a reference group, the hazard ratio of group I was 2.23 [95\% confidence interval $(\mathrm{Cl}) 1.21-4.11, \mathrm{p}=$ 0.01 ] and group III was 0.89 ( $95 \% \mathrm{Cl} 0.47-1.71, \mathrm{p}=0.74)$. The serum uric acid levels correlated inversely with Col scores $(r=$ $-0.31,95 \% \mathrm{Cl}-0.44$ to $-0.17, \mathrm{p}<0.0001$ ) and positively with serum albumin levels ( $r=0.35,95 \% \mathrm{Cl} 0.21-0.48, \mathrm{p}<0.0001)$. Conclusion: Low serum uric acid is a mortality risk factor in incident hemodialysis patients with a high comorbidity burden and hypoalbuminemia.

Copyright $\odot 2008$ S. Karger AG, Basel
\end{abstract}

\section{Introduction}

An elevated serum uric acid is consistently associated with increased cardiovascular risk in the general population, in part because patients with hypertension, metabolic syndrome and chronic kidney disease frequently have elevated uric acid levels [1]. Hyperuricemia is also common in subjects with end-stage renal disease, where it has been reported in up to $50 \%$ of subjects $[2,3]$. Consistent with studies in the general population, 2 studies performed in hemodialysis (HD) patients ( 1 in Sweden [3] and 1 in Taiwan [2]) confirmed that hyperuricemia is also associated with a significantly increased mortality risk in the dialysis population.

While high serum uric acid levels appear to be consistently associated with increased cardiovascular risk, many studies in the general population have also shown a J-shaped curve, in which low uric acid levels also confer increased mortality risk. The 2 studies in HD patients noted that lower uric acid levels also increased mortality risk, although in both studies this did not reach statistical significance $[2,3]$. Almost nothing is known about why subjects with low uric acid levels are at an increased risk for mortality. It has been postulated that a low uric acid level could translate into greater oxidative stress, since

R.J.J. has several patent applications on the role of uric acid in cardiovascular disease.

\section{KARGER}

๑ 2008 S. Karger AG, Basel

Fax +41613061234 E-Mail karger@karger.ch www.karger.com www.karger.com/ajn
S.M. Kurt Lee, MD

Biotronics Kidney Center 2755 Liberty Ave.

Beaumont, TX 77702 (USA)

Tel. +1 409892 1003, Fax +1 409892 2655, E-Mail Kurt4915@sbcglobal.net 
uric acid is a known antioxidant [4]. Alternatively, since uric acid is largely dependent on diet, a low uric acid level could reflect malnutrition [2].

In this study we hypothesized that a low serum uric acid level is a mortality risk factor associated with clinical markers of oxidative stress in a cohort of American HD outpatients. We found low uric acid levels conferred a greater than 2-fold risk for death, whereas elevated uric acid was not associated with increased mortality risk. We therefore undertook a detailed analysis to better understand the potential mechanism by which a low uric acid level might confer increased risk in this population. We found that in our patients, low uric acid levels were associated with markers of malnutrition and a high comorbidity burden, which is consistent with the hypothesis that oxidative stress might contribute to the increased mortality in these patients.

\section{Methods}

\section{Patients}

The retrospective longitudinal observational study was conducted at a single outpatient dialysis center. All incident patients who started HD between January 1, 1998, and December 31, 2004, were included in the study. Data collection was terminated either at the end of the study period or in the event that the patient received a renal transplant, had recovery of renal function, or expired. Excluded from the study were the following: (1) all prevalent patients who had started HD before January 1, 1998; (2) all transient patients who were transferred to the Biotronics Kidney Center from another unit and who had received less than 1 month of HD; (3) all peritoneal dialysis patients who had received more than 3 months of peritoneal dialysis; (4) all lost patients who were transferred out of the Biotronics Kidney Center to another unit without adequate follow-up clinical information, and (5) all patients who had the following medical conditions that may affect serum uric acid levels: (a) malignant diseases; (b) a malignant disease with current usage of chemotherapies; (c) acquired immune deficiency disease with concurrent usage of antiviral agents, and (d) an established history of alcohol abuse and/or liver cirrhosis.

The first author (S.M.K.L.) provided the day-to-day nephrology care for the studied patients according to accepted standard nephrology practice. HD prescriptions and anemia management strategies, including erythropoietin dosages and nutritional interventions, were adjusted weekly (or more frequently, if needed) to meet target values for urea reduction rate (URR), serum hematocrit and serum albumin (S-albumin) levels according to the $\mathrm{Di}$ alysis Outcome and Quality Initiatives (K/DOQI) guidelines [5].

\section{Data Collection and Comorbidity Assessments}

At the initiation of dialysis, each subject was evaluated for the presence or absence of each of the comorbid factors listed on the Medicare evidence 2728 form [6]. Baseline socioeconomic, demographic and predialysis laboratory information was also abstracted from the Medicare evidence 2728 form. The medical record of each of the study subjects was reviewed to verify the accuracy of the comorbid conditions entered in the Medicare form. This information was entered only by S.M.K.L. For patients who were transferred from another dialysis unit, the Medicare evidence 2728 form completed by the outside nephrologist was reviewed by S.M.K.L. to ensure the accuracy of the intake information. For missing information, S.M.K.L. reviewed the private office records, hospital records, transfer notes and/or directly interviewed the patients in order to fill in all the relevant information for analysis. A primary diagnosis of end-stage renal disease was recorded by S.M.K.L. for each of the studied patients. For each comorbid condition present, a score was assigned according to a scoring system (the Comorbidity Index score), as outlined in Appendix 1 [7]. A total score was recorded for each patient.

The study was approved by the local hospital Institutional Review Board, which also served as the sponsoring center for this study. The individual identities of the patients were masked and the data collected reflects the aggregate effects of clinical and laboratory information with no additional risk to the individual patient. The need for obtaining an informed consent for the study from an individual patient was therefore waived, similar to the approach reported by Hsu et al. [8].

Core Indicator Values

On the first Monday or Tuesday of each month, pre- and postdialysis blood samples from each of the patients was collected. The core indicators were URR, serum hematocrit and S-albumin levels. The target value for URR was $\geq 65 \%$, that of serum hematocrit was $\geq 33 \mathrm{~g} \%$ and that of S-albumin was $\geq 3.5 \mathrm{~g} / \mathrm{dl}$. For patients that had core indicator values that fell below the target values, the appropriate laboratory test was repeated on the following Monday or Tuesday. Prescription adjustments were made following K/DOQI guidelines through a Continuous Quality Improvement program, using established protocols. The mean values of the core indicators for each patient over the entire study period were employed for final analysis.

The 'slow flow' method for postdialysis blood sampling, as recommended by K/DOQI guidelines, was used to determine the URR [5]. The bromocresol green method was used to determine S-albumin levels. Serum hematocrit and S-albumin levels were determined using predialysis blood samples.

Serum uric acid was measured by an autoanalyzer [9] once a month before the initiation of dialysis. Patients were stratified into the following groups according to the concentration of serum uric acid: group I, $\leq 5.2 \mathrm{mg} / \mathrm{dl}(310 \mu \mathrm{mol} / \mathrm{l} ;<20$ th percentile); group II, $5.2-7.69 \mathrm{mg} / \mathrm{dl}(309-457 \mu \mathrm{mol} / \mathrm{l}$; 20 th to 80 th percentile); group III, $\geq 7.7 \mathrm{mg} / \mathrm{dl}$ ( $458 \mu \mathrm{mol} / \mathrm{l} ;>80$ th percentile).

\section{Body Mass Index}

At the inception of dialysis, the height (in meters) and the weight (in kilograms) were recorded for each patient. Their body mass index (BMI) was calculated using the formula: $\mathrm{BMI}=$ weight $(\mathrm{kg}) /$ height $\left(\mathrm{m}^{2}\right)$.

\section{Medication Usage}

All diuretics were discontinued at the inception of dialysis. All patients were treated with routine antihypertensive mediations, phosphate binders and other medications that were deemed necessary, according to the current standard practice of nephrology. 
Calculation of Mortality Rates and Estimation of Risk of

Death

The mortality rate was expressed as the number of deaths per 100 person-months of HD treatment in each of the 3 uric acid severity groups. The number of treatment months of HD exposure was recorded for each of the uric acid severity groups. The theoretical number of months of exposure to HD was calculated as the number of treatment months divided by 13 , assuming that there are on the average 13 treatments per month. The mortality rate was calculated as: number of deaths/number of patients/theoretical number of treatment months of exposures to HD $\times 100$.

The risk of deaths in each of the uric acid severity groups was estimated using a Cox proportional-hazard regression model, expressed as hazard ratios (HR). Group II patients served as the reference group.

\section{Statistical Analysis}

Student's t test was used to analyze the differences between 2 mean values. Pearson's correlation coefficient was used to analyze the relationship between 2 continuous variables. To analyze the relationship between 2 proportions, Fisher's exact test was used for samples of less than 20, and for samples of greater than 20 the $\chi^{2}$ test was used. The relationships between 2 or more groups of data were analyzed using the Kruskal-Wallis test or $\chi^{2}$ test, as deemed appropriate. The Kolmogorov-Smirnov test was used to analyze the distribution of a group of continuous data for the presence of a normal distribution. A Cox proportional-hazard regression model was used to estimate the risk of deaths with discrete clinical parameters. $\mathrm{p} \leq 0.05$ was considered statistically significant. All statistical analyses were performed using the Medcalc for Windows software, version 7.4.1.0 (Medcalc Software, Mariakerke, Belgium).

\section{Results}

Of 207 incident patients referred to the dialysis center during the study period, 18 were transferred out of the unit with no follow-up clinical information, 6 patients recovered renal function and 6 patients received a renal transplant. Patients with cancer $(\mathrm{n}=12)$, alcohol abuse $(n=6)$, acquired immunodeficiency disease $(n=2)$ and amyloidosis $(n=1)$ were also excluded, as outlined in the protocol. In total, 168 incident patients were eligible for final analysis. The mean number of treatment sessions per patient was $168 \pm 148$ (range $1-614$ ). The mean duration of treatment exposure per patient was $13.6 \pm 11.9$ months (range 1-49 months).

\section{Patient Characteristics and Descriptive Statistics}

There were 86 female (51\%), 87 black (52\%), 75 white (45\%), 4 Asian (2.4\%) and 2 Hispanic (1.2\%) patients. The mean age of the patients was $59.3 \pm 16.2$ years (range 16-98 years). The mean BMI was $28.4 \pm 7.4$ (range 15.856.7). The mean Comorbidity Index score was $11.5 \pm 6.3$ (range 0-29). Eighty-five (51\%) of the subjects had diabetes, 49 (29\%) had hypertension, 13 (8\%) had glomerulonephritis, 7 (4\%) had unknown causes, 4 (2.4\%) had acquired obstructive uropathy, 4 (2.4\%) had polycystic kidney diseases, 2 (1\%) had non-recovered acute tubular necrosis, 2 (1\%) had cholesterol emboli, 1 (0.5\%) had nephrocalcinosis and $1(0.5 \%)$ had vasculitis as their etiology of underlying renal diseases.

The mean serum uric acid level was $6.7 \mathrm{mg} / \mathrm{dl}$ (399 $\mu \mathrm{mol} / \mathrm{l})$, the range was $3.98-10.7 \mathrm{mg} / \mathrm{dl}$ (237-636 $\mu \mathrm{mol} / \mathrm{l})$. The mean serum uric acid level in the male cohort $[6.92 \mathrm{mg} / \mathrm{dl}(412 \mu \mathrm{mol} / \mathrm{l})]$ was higher than that in the female cohort [6.43 mg/dl $(382 \mu \mathrm{mol} / \mathrm{l}), \mathrm{p}=0.0042]$. The Kolmogorov-Smirnov test showed the mean of the first month's serum uric acid values $(p=0.374)$ and the mean serum uric acid values ( $\mathrm{p}=0.546)$ followed a normal distribution. The mean serum uric acid level among AfricanAmerican patients was $6.94 \pm 1.27 \mathrm{mg} / \mathrm{dl}(413 \pm 76$ $\mu \mathrm{mol} / \mathrm{l})$ and was higher than that observed in white patients $[6.37 \pm 0.90 \mathrm{mg} / \mathrm{dl}(379 \pm 54 \mu \mathrm{mol} / \mathrm{l}), \mathrm{p}=0.0014]$. Asian and Hispanic patients were not included in the analysis because of the small sample sizes for these groups.

\section{Uric Acid Levels in Relation to Etiology of Renal \\ Disease}

Among the patients who had diabetes as the etiology of their renal disease, the mean serum uric acid level was $6.48 \pm 1.05 \mathrm{mg} / \mathrm{dl}(385 \pm 62 \mu \mathrm{mol} / \mathrm{l})$ and was lower than that of the patients who did not have diabetes $[6.86 \pm 1.19$ $\mathrm{mg} / \mathrm{dl}(408 \pm 71 \mu \mathrm{mol} / \mathrm{l}), \mathrm{p}=0.03$ ]. Subjects with hypertension-associated renal disease had higher uric acid levels $[7.07 \pm 1.31 \mathrm{mg} / \mathrm{dl}(421 \pm 78 \mu \mathrm{mol} / \mathrm{l})]$ than those who did not have hypertension $[6.52 \pm 1.03 \mathrm{mg} / \mathrm{dl}(388 \pm 61$ $\mu \mathrm{mol} / \mathrm{l}), \mathrm{p}=0.005]$. There was no difference between the mean serum uric acid level in patients who had glomerulonephritis $[7.00 \pm 1.61 \mathrm{mg} / \mathrm{dl}(416 \pm 96 \mu \mathrm{mol} / \mathrm{l})]$ and those who did not $[6.65 \pm 1.27 \mathrm{mg} / \mathrm{dl}(396 \pm 26 \mu \mathrm{mol} / \mathrm{l})$, $\mathrm{p}=0.3]$.

\section{Uric Acid Levels in Relation to Comorbid Conditions}

Table 1 shows the distribution of comorbid conditions among the studied patients, which were further stratified into 3 serum uric acid severity groups. Group I patients had serum uric acid levels in the lowest quintile [ $\leq 5.2 \mathrm{mg} /$ $\mathrm{dl}(310 \mu \mathrm{mol} / \mathrm{l})]$, those in group II had levels in the middle 3 quintiles, and those in group III had levels in the highest quintile $[\geq 7.7 \mathrm{mg} / \mathrm{dl}(458 \mu \mathrm{mol} / \mathrm{l})]$. The $\chi^{2}$ test was used to analyze the relationship between each individual comorbid condition and the 3 serum uric acid groups. Our data show a higher prevalence of comorbidity compared to na- 
Table 1. Distribution of comorbid conditions and functional status in the 3 uric acid severity groups

\begin{tabular}{|c|c|c|c|c|c|c|c|c|c|}
\hline \multirow[t]{2}{*}{ Comorbid conditions } & \multicolumn{2}{|c|}{ Whole group } & \multicolumn{2}{|c|}{ Group I } & \multicolumn{2}{|c|}{ Group II } & \multicolumn{2}{|c|}{ Group III } & \multirow[t]{2}{*}{$\mathrm{p}$ value } \\
\hline & $\mathrm{n}$ & $\%$ & $\mathrm{n}$ & $\%$ & $\mathrm{n}$ & $\%$ & $\mathrm{n}$ & $\%$ & \\
\hline Congestive heart failure & 147 & 88 & 14 & 88 & 109 & 89 & 24 & 83 & 0.89 \\
\hline Ischemic heart disease & 113 & 67 & 11 & 69 & 83 & 67 & 19 & 66 & 0.97 \\
\hline Myocardial infarction & 22 & 13 & 1 & 6 & 19 & 15 & 2 & 11 & 0.0003 \\
\hline Cardiac arrest & 4 & 2 & 0 & 0 & 4 & 3 & 0 & 0 & NA \\
\hline Cardiac arrhythmia & 30 & 18 & 0 & 0 & 25 & 20 & 5 & 17 & 0.054 \\
\hline Cerebrovascular disease & 39 & 23 & 7 & 44 & 26 & 21 & 6 & 21 & 0.0021 \\
\hline Peripheral vascular disease & 102 & 61 & 12 & 75 & 76 & 62 & 14 & 48 & 0.05 \\
\hline History of hypertension & 135 & 80 & 12 & 75 & 98 & 80 & 25 & 86 & 0.69 \\
\hline Diabetes (primary/contributing) & 77 & 46 & 10 & 63 & 60 & 49 & 7 & 24 & 0.0002 \\
\hline Diabetes (currently on insulin) & 40 & 24 & 6 & 38 & 29 & 24 & 6 & 17 & 0.013 \\
\hline Chronic obstructive lung disease & 19 & 11 & 1 & 6 & 11 & 9 & 4 & 1 & 0.00008 \\
\hline Inability to ambulate & 47 & 28 & 11 & 69 & 30 & 24 & 6 & 2 & $<0.00001$ \\
\hline Inability to transfer & 23 & 14 & 8 & 50 & 14 & 11 & 1 & 3 & $<0.00001$ \\
\hline
\end{tabular}

$\mathrm{NA}=$ Not analyzed

Table 2. Comparison of clinical characteristics in the 3 serum uric acid severity groups

\begin{tabular}{|c|c|c|c|c|}
\hline Clinical parameters & Group I $(n=16)$ & Group II $(\mathrm{n}=123)$ & Group III $(n=29)$ & $\mathrm{p}$ value \\
\hline Age, years & $66.3 \pm 11.6$ & $60.2 \pm 16.2$ & $52 \pm 15$ & 0.0015 \\
\hline Mortality rate per 100 person-months & 5.59 & 0.25 & 0.71 & 0.0046 \\
\hline Duration of treatment, months & $11.3 \pm 11.2$ & $13.8 \pm 12.5$ & $13.4 \pm 9.6$ & 0.67 \\
\hline Serum uric acid level, mg/dl & $4.8 \pm 0.36$ & $6.49 \pm 0.65$ & $8.43 \pm 0.76$ & $<0.0001$ \\
\hline BMI & $29.6 \pm 8.5$ & $27.8 \pm 7$ & $30.2 \pm 8.3$ & 0.36 \\
\hline Comorbidity Index score & $15.6 \pm 5.8$ & $11.64 \pm 6.3$ & $8.5 \pm 5.4$ & 0.0005 \\
\hline URR, \% & $73 \pm 5.62$ & $70 \pm 8.65$ & $69.4 \pm 3.59$ & 0.08 \\
\hline Percentage of patients with URR $\geq 65 \%$ & 88 & 85 & 86 & 0.99 \\
\hline Serum hematocrit, g\% & $35.2 \pm 3.9$ & $35.4 \pm 2.69$ & $35.4 \pm 2.23$ & 0.89 \\
\hline Percentage of patients with hematocrit $\geq 33 \mathrm{~g} \%$ & 81 & 89 & 86 & 0.83 \\
\hline S-albumin level, g/dl & $3.34 \pm 0.7$ & $3.41 \pm 0.44$ & $3.73 \pm 0.37$ & $<0.0001$ \\
\hline Percentage of patients with S-albumin $\geq 3.5 \mathrm{~g} / \mathrm{dl}$ & 56 & 53 & 83 & 0.014 \\
\hline
\end{tabular}

Data are means \pm standard deviation unless stated otherwise.

tional estimates, with increased rates of congestive heart failure (88\%), diabetes mellitus (70\%), cerebrovascular disease (23\%), inability to ambulate (28\%) and inability to transfer (14\%). The corresponding data from the general population of the USA were $32,23,9,4$ and $1.5 \%$, respectively, during the study period (from 1998 to 2004) [10].

The mean serum uric acid level of the patients with individual comorbid conditions was compared with patients who did not have the condition. A statistically significant difference was found among the following comorbid conditions:
(1) cerebrovascular accident [present vs. absent, 6.31 \pm 1.23 vs. $8.78 \pm 1.09 \mathrm{mg} / \mathrm{dl}(375 \pm 73$ vs. $522 \pm 65$ $\mu \mathrm{mol} / \mathrm{l}), \mathrm{p}=0.02$;

(2) peripheral vascular disease [present vs. absent, 6.5 \pm 1.04 vs. $6.92 \pm 1.23 \mathrm{mg} / \mathrm{dl}(387 \pm 62$ vs. $412 \pm 73$ $\mu \mathrm{mol} / \mathrm{l}), \mathrm{p}=0.02$;

(3) inability to ambulate [present vs. absent, 6.29 \pm 1.07 vs. $6.88 \pm 1.12 \mathrm{mg} / \mathrm{dl}(374 \pm 64$ vs. $409 \pm 67$ $\mu \mathrm{mol} / \mathrm{l}), \mathrm{p}=0.001$;

(4) inability to transfer [present vs. absent, $5.90 \pm 1.00$ vs. $6.83 \pm 1.10 \mathrm{mg} / \mathrm{dl}(351 \pm 59$ vs. $406 \pm 65 \mu \mathrm{mol} / \mathrm{l})$, $\mathrm{p}=0.0001]$. 
Table 2 summarizes the clinical parameters of the patients in the 3 uric acid severity groups.

Table 3 summarizes the HRs of the clinical parameters that conferred a risk of death in group I patients compared with the references group. In this analysis, we included patients with diabetes as an etiology and as a comorbid condition in 1 group. Similarly, we included patients with hypertension as an etiology and as a comorbid condition in 1 group. The following comorbid conditions were not analyzed because of their small sample sizes: myocardial infarction, cardiac arrest, cardiac arrhythmia and chronic obstructive lung disease. The HR for congestive heart failure, ischemic heart disease, cerebrovascular disease and inability to ambulate did not show statistically significant differences when compared with group II. The same analysis was performed with group III patients compared with the reference group, and the HR of the all tested clinical parameters did not reach statistically significant levels.

The Comorbidity Index scores correlate inversely with the mean serum uric acid levels $[r=-0.31,95 \%$ confidence interval (CI) -0.044 to $-0.17, \mathrm{p}<0.0001]$.

\section{Causes of Death}

There were 19 patients who died of infectious complications, of whom 15 died from sepsis and 2 died of pneumonia. Nineteen patients died of cardiovascular complications, of whom 4 died of acute myocardial infarction, 2 of cardiomyopathy, 3 of cardiac arrhythmias, 7 of cardiac arrest and 3 of pulmonary edema. There were $19 \mathrm{pa}-$ tients who died from other causes, of whom 11 patients withdrew from dialysis, 1 died of hyperkalemia, 1 died from pancreatitis, 1 died of malignant disease and 5 died of unknown causes.

The average serum uric acid level of the survivors [6.9 $\pm 1.1 \mathrm{mg} / \mathrm{dl}(407 \pm 65 \mu \mathrm{mol} / \mathrm{l})]$ was higher than that of the expired patients $[6.3 \pm 1.2 \mathrm{mg} / \mathrm{dl}(377 \pm 68 \mu \mathrm{mol} / \mathrm{l})]$ and the difference was statistically significant $(\mathrm{p}=$ 0.0053).

\section{Other Correlations with Uric Acid}

There was a statistically significant correlation between the mean serum uric acid level and the BMI ( $\mathrm{r}=$ $0.21,95 \%$ CI 0.06-0.35, $\mathrm{p}=0.0066$ ). There was also a statistically significant inverse correlation between the mean serum uric acid level and age $(\mathrm{r}=-0.36,95 \%$ CI -0.49 to $-0.23, p<0.0001)$. In contrast, the mean serum uric acid level had no statistically significant relationship with the mean serum hematocrit level ( $r=0.0197,95 \%$ CI -0.13 to $0.17, p=0.8$ ). The mean serum uric acid level correlates with the mean serum albumin level $(r=0.35,95 \%$
Table 3. HRs for mortality risk factors

\begin{tabular}{llll}
\hline Risk factors & HR & $\begin{array}{l}95 \% \text { CI } \\
\text { for HR }\end{array}$ & p value \\
\hline Diabetes mellitus & 2.4 & $1.05-5.59$ & 0.04 \\
Peripheral vascular disease & 2.4 & $1.09-5.32$ & 0.03 \\
Hypertension & 2.2 & $0.17-1.35$ & 0.05 \\
African-American ethnicity & 4.5 & $1.60-12.41$ & 0.004 \\
Age $\geq 65$ & 2.2 & $1.00-4.92$ & 0.05 \\
BMI $\geq 24.9$ & 2.6 & $1.07-6.09$ & 0.04 \\
Inability to transfer & 2.6 & $1.01-6.47$ & 0.05 \\
\hline
\end{tabular}

Data compare HRs for mortality risk factors in patients with low serum uric acid levels (group I) with those in the reference group, who had normal serum uric acid levels (group II), using a Cox regression model.

CI $0.21-0.48, \mathrm{p}<0.0001)$ and inversely with the mean URR ( $r=-0.17,95 \%$ CI -0.32 to $-0.02, p=0.02)$. The relationship between the 3 graded serum uric acid groups with the core indicator values and other clinical parameters is summarized in table 2 .

\section{Uric Acid Levels, Mortality and Risk of Death}

In group I $(n=16)$, there were 11 deaths, the patients received 160 treatment sessions and had a mortality rate of 5.59/100 person-months. In group II $(n=123)$, there were 41 deaths, the patients received 1,711 treatment sessions and had a mortality rate of $0.25 / 100$ personmonths. In group III $(n=29)$, there were 6 deaths, the patients received 380 treatment sessions and had a mortality rate of $0.71 / 100$ person-months. When the mortality rate of group I was compared with that of group II, $\mathrm{p}=0.01$ and group II compared with group III, $\mathrm{p}=$ 0.16 .

Using group II as a reference group, the HR of group I was $2.23(95 \% \mathrm{CI} 1.21-4.11, \mathrm{p}=0.01)$ and that of group III was 0.89 (95\% CI $0.47-1.71, \mathrm{p}=0.74)$.

\section{Uric Acid Levels and Vintage Effect}

There is a positive and statistically significant correlation between the first month's serum acid levels and the mean serum uric acid levels $(r=0.72,95 \%$ CI $0.64-0.79$, $\mathrm{p}<0.0001$ ). The first month's serum uric acid level is equivalent to the serum uric acid level before the initiation of dialysis at the outpatient dialysis center.

\section{Uric Acid Levels and Medication Usage}

There was no impact of medication usages on serum uric acid levels, as evidenced by the stability of serum uric 
acid levels between the first month's serum uric acid levels and the average serum uric acid levels trended over the entire observation period.

\section{Discussion}

In this study we examined the relationship between serum uric acid and mortality risk in a dialysis unit in the USA. The principal finding was that uric acid levels in the lowest quintile $(<5.2 \mathrm{mg} / \mathrm{dl})$ were associated with a greater than 2-fold increased risk for death in the first year of dialysis. While a high uric acid level $(>9.0 \mathrm{mg} / \mathrm{dl})$ tended to also show an increased risk for death, this latter finding did not reach statistical significance. The findings of this study are, therefore, distinct from what has been observed in the general population in the USA [1], as well as in previous studies of HD patients in Taiwan [2] and Sweden [3].

A number of factors regulate uric acid in the HD patient. Dietary intake of purines and fructose is a primary source of uric acid, and so levels could vary with nutritional status. Since the kidney eliminates much of the uric acid generated, a decrease in the glomerular filtration rate is associated with an increase in blood uric acid levels (although there is a compensatory increase in gut elimination). Uric acid is also an antioxidant, and upon reaction with oxidants it will undergo degradation to allantoin and other products [11]. In HD patients, this degradation pathway is increased 5-fold or more [12] and dialysis itself will also remove approximately $1 \mathrm{~g}$ of uric acid per dialysis session [2]. Finally, a variety of demographic factors and comorbid conditions are associated with an abnormal serum uric acid level in the general and HD populations [1-3]. In this study, we found that AfricanAmerican ethnicity, hypertension, obesity and male gender were associated with higher uric acid levels, which is consistent with the results reported previously $[2,3]$.

Given the large number of factors that can modulate uric acid levels, we undertook a detailed analysis to determine the relationship between low uric acid levels and comorbid conditions. In this regard, we were able to show that a low serum uric acid level was associated with protein energy wasting (as reflected by low S-albumin levels) and by the presence of marked comorbid conditions including diabetes mellitus, peripheral vascular disease, functional impairments, older age and higher Comorbidity Index scores (table 3). This syndrome of malnutrition and protein energy wasting is often linked with increased oxidative stress and inflammation, and it has been linked with increased mortality in patients with end-stage renal disease [13-15]. In this regard, the 'reverse epidemiology' we have observed between uric acid and overall mortality in this study is not distinct from that observed with other cardiovascular risk factors, including blood pressure, BMI, serum cholesterol, serum creatinine and serum homocysteine levels [13-15]. Indeed, the more profound relationship between low uric acid and mortality in this study, as compared to the 2 prior studies in dialysis patients, likely reflects the greater frequency of comorbidity and protein energy wasting in the US dialysis population [16].

The term 'reverse epidemiology' is also known as 'risk factor reversal' and 'paradoxical risk factors' [17]. Several mechanisms were proposed to explain this observation [18]. The association of obesity with the paradoxical survival outcome (obesity paradox) is illustrative of this concept, as reviewed by Kalantar-Zadeh et al. [18]. In this example, undernourished individuals have a shorter survival time due to discrepancies in the time of appearances of competitive risk factors. The data from our study seem to support this concept. We found that the predialysis S-albumin levels were not statistically different between the diabetics in group I and those in group II (2.98 $\pm 0.71 \mathrm{~g} / \mathrm{dl}$ in group I vs. $3.27 \pm 0.63 \mathrm{~g} / \mathrm{dl}$ in group II, $\mathrm{p}=0.18$ ) before the initiation of dialysis. After the start of dialysis, the mean S-albumin levels in group I were not statistically different from the predialysis level (2.98 \pm 0.71 vs. $3.06 \pm 0.59 \mathrm{~g} / \mathrm{dl}$, respectively, $\mathrm{p}=0.78$ ). However, in the diabetic patients in group II, they were able to achieve higher levels of S-albumin, which were statistically different from the predialysis values $(3.27 \pm 0.63 \mathrm{vs}$. $3.46 \pm 0.4 \mathrm{~g} / \mathrm{dl}$, respectively, $\mathrm{p}=0.036$ ). Therefore, the diabetic patients with low serum uric acid levels associated with hypoalbuminemia had a higher risk of death probably from the 'short-term killer' effects of oxidative stress characterized by hypoalbuminemia and/or the loss of antioxidant effects of low serum uric acid levels. This 'short-term killer' effect overrides the long-term effects of other competitive risk factors, such as hypertension. Furthermore, serum uric acid may also be a nutritional marker associated with hypoalbuminemia, displaying a uric acid paradox in our patients.

In this study, the sample sizes in the 3 uric acid severity groups were not equal, with relatively small sample sizes in group I and group III. However, the cohort time for this study was quite long (6 years), giving it strength over previous studies $[2,3]$ in which the cohort times were only 1 year.

A limitation of this study is that it was conducted in a single center. It is possible that, because of cultural or de- 
mographic factors, the population of South East Texas may not be representative of the true prevalence of the comorbid conditions in the general population in the USA. A second limitation is that this study does not determine if the low uric acid level contributes to the oxidative stress associated with the protein energy wasting syndrome, or whether it is simply reflecting poorer nutrition in this population.

In conclusion, our results suggest that uric acid is similar to other cardiovascular risk factors in that there is a reverse epidemiology pattern in HD patients. This relationship is largely explained by the association of low uric acid levels with comorbid conditions and markers of protein energy wasting that are suggestive of higher oxidative stress. Further studies are necessary to understand if the low serum uric acid level is the cause or consequence of these conditions.

\section{Appendix 1}

Values used to calculate Comorbidity Index scores

Drug use

Inability to ambulate

Cancer

Diabetes

Inability to transfer

Congestive heart failure

Chronic obstructive lung disease

Cardiac arrest

Cerebral vascular accident

Alcohol abuse

Diabetes with insulin usage

Smoker

Peripheral vascular disease

Ischemic heart disease

Cardiac arrhythmia

Myocardial infarction

\section{Acknowledgements}

We thank St. Elizabeth Hospital, Beaumont, Tex., USA, for providing administrative assistance and Institutional Review Board sponsorship in the preparation of this manuscript. R.J.J. is supported by US Public Health grants DK-52121 and HL-68607.

\section{References}

1 Johnson RJ, Kang DH, Feig D, Kivlighn S, Kanellis J, Watanabe S, Tuttle KR, Rodriguez-Iturbe B, Herrera-Acosta J, Mazzali M: Is there a pathogenetic role for uric acid in hypertension, cardiovascular and renal disease? Hypertension 2003;41:1183-1190.

2 Hsu SP, Pai MF, Peng YS, Chiang CK, Ho TI, Hung KY: Serum uric acid levels show a 'Jshaped' association with all-cause mortality in haemodialysis patients. Nephrol Dial Transplant 2004;19:457-462.

- 3 Suliman ME, Johnson RJ, Garcia-Lopez E, Qureshi AR, Molinai H, Carrero JJ, Heimburger O, Barany P, Axelsson J, Lindholm B, Stenvinkel P: J shaped mortality relationship for uric acid in CKD. Am J Kidney Dis 2006; 48:761-771.

-4 Ames BN, Cathcart R, Schwiers E, Hochstein $P$ : Uric acid provides an antioxidant defense in humans against oxidant- and radicalcaused aging and cancer: a hypothesis. Proc Natl Acad Sci USA 1981;78:6858-6862.

5 National Kidney Foundation: K/DOQI clinical practice guidelines for chronic kidney disease: evaluation, classification, and stratification. Am J Kidney Dis 2002;39(2 suppl 1):S1-S266.

Low Serum Uric Acid and Mortality in Hemodialysis Patients
6 US Renal Data System: 1999 Annual Data Report. Bethesda, National Institutes of Health, 1999, pp Li-Lvi.

7 Wolfe RA, Ashby VB, Port FK: 1993 DMMS Comorbidity Index validated by medical evidence form data. J Am Soc Nephrol 2000;11: $247 \mathrm{~A}$.

$\checkmark 8$ Hsu CY, McCullouch CE, Iribarren C, Darbinian J, Go AS: Body mass index and risk for end-stage renal disease. Ann Intern Med 2006; 144:21-28.

-9 Fossati P, Prencipe L, Berti G: Use of 3,5-dichloride-2-hydroxybenzenesulfonic acid/4aminophenazone chromomeric system in direct enzymic assay of uric acid in serum and urine. Clin Chem 1980;26:227-231.

10 US Renal Data System: 2007 Annual Data Report. Bethesda, National Institutes for Health, 2007, p 93.

11 Kand’ar R, Záková P, Muzáková V: Monitoring of antioxidant properties of uric acid in humans for a consideration measuring of levels of allantoin in plasma by liquid chromatography. Clin Chim Acta 2006;365:249256.

12 Sorenson LB: Role of the intestinal tract in the elimination of uric acid. Arthritis Rheum 1965;8:694-706.
13 Kalantar-Zadeh K, Horwich TB, Oreopoulos A, Kovesdy CP, Younessi H, Anker SD, Morley JE: Risk factor paradox in wasting diseases. Curr Opin Clin Nutr Metab Care 2007; 10:433-442.

14 Carrero JJ, Qureshi AR, Axelsson J, Avesani CM, Suliman ME, Kato S, Barany P, SnaedalJonsdottir S, Alvestrand A, Heimburger P, Lindholm B, Stenvinkel P: Comparison of nutritional and inflammatory markers in dialysis patients with reduced appetite. Am J Clin Nutr 2007;8:695-701.

15 Stenvinkel P: Inflammation in end-stage renal disease: the hidden enemy. Nephrology (Carlton) 2006;11:36-41.

16 Goodkin DA, Young EW, Kurokawa K, Prütz KG, Levin NW: Mortality among hemodialysis patients in Europe, Japan, and the United States: case-mix effects. Am J Kidney Dis 2004;44(suppl 2):16-21.

17 Kopple JD: The phenomenon of altered risk factor patterns or reverse epidemiology in persons with advanced chronic kidney failure. Am J Clin Nutr 2005;81:1257-1266.

18 Kalantar-Zadeh K, Block G, Humphreys $\mathrm{MH}$, Kopple J: Reverse epidemiology of cardiovascular risk factors in maintenance dialysis patients. Kidney Int 2003;63:793-808. 